\title{
A randomized, double-blind study of the ultrasound assessment of the effect of pharyngeal packing on perioperative gastric volume in nasal surgery
}

M. Emrah Temel ${ }^{1}$, Tolga Totoz ${ }^{2}$, Kerem Erkalp ${ }^{3 *}$, Gulen Safiye Temel ${ }^{1}$ and Aysin Selcan ${ }^{3}$

\begin{abstract}
Background: Pharyngeal packing (PP) is commonly performed to reduce the incidence of perioperative blood ingestion (PBI) in nasal surgery (NS), and thus the incidence and severity of postoperative nausea and vomiting (PONV). This study examined the effects of PP on the perioperative gastric volume (GV) and PONV in patients undergoing NS, by ultrasound assessment.

Methods: Patients undergoing elective NS [septoplasty, septo-rhinoplasty (SRP) and functional endoscopic sinus surgery (FESS)] were randomised to receive or not receive PP. In the PP group, pharyngeal packs were placed after the orotracheal intubation. Ultrasound assessments were performed for all patients preoperatively (before the anaesthesia induction) and postoperatively (before the extubation). The antero-posterior (AP) and cranio-caudal (CC) antral diameters, antral cross-sectional area (ACSA), and total GV were calculated. PONV incidence and severity were rated. These variables were compared between timepoints and groups, and in the subgroup analyses according to the surgery type. Pearson correlation analysis was performed to assess correlations between the variables.
\end{abstract}

Results: AP and CC diameters and ACSAs were greater postoperatively than preoperatively in the PP and non-PP groups $(n=44$ each; all $p<0.05)$. Postoperative AP and CC diameters and the ACSA were greater in the non-PP than in the PP group (all $p<0.05$ ). Postoperative AP diameters were greater than preoperatively in patients undergoing SRP and FESS, and the postoperative CC diameter and ACSA were greater than preoperatively in patients undergoing SRP (all $p<0.05$ ). Surgery duration was correlated positively with postoperative AP diameter $(r=0.380, p<0.05)$, CC diameter $(r=0.291$, $p<0.05)$, and ACSA $(r=0.369, p<0.05)$. Patients who underwent septoplasty surgery, PP was decreased PONV incidence and severity at the first four hours, postoperatively $(p<0.05)$.

Conclusions: The study findings indicate that PP reduces the increase in the perioperative GV due to PBI in an elective NS. It is therefore a useful and safe means of reducing the risk of perioperative pulmonary aspiration in such surgeries.

Trial registration: Australian New Zealand Clinical Trials Registry (ANZCT), ACTRN12619000487112, 25/03/2019, Trial registration retrospectively registered.

Keywords: Pharyngeal packing, Postoperative nausea and vomiting, Ultrasonography, Gastric volume

\footnotetext{
*Correspondence: keremerkalp@hotmail.com

${ }^{3}$ Health Sciences University, Istanbul Bagcilar Training and Educational

Hospital, Istanbul, Turkey

Full list of author information is available at the end of the article
}

(c) The Author(s). 2019 Open Access This article is distributed under the terms of the Creative Commons Attribution 4.0 International License (http://creativecommons.org/licenses/by/4.0/), which permits unrestricted use, distribution, and reproduction in any medium, provided you give appropriate credit to the original author(s) and the source, provide a link to the Creative Commons license, and indicate if changes were made. The Creative Commons Public Domain Dedication waiver (http://creativecommons.org/publicdomain/zero/1.0/) applies to the data made available in this article, unless otherwise stated. 


\section{Background}

The incidence of postoperative nausea and vomiting (PONV) due to perioperative blood ingestion (PBI) in nasal surgery (NS) has been observed in the $34-60 \%$ of the patients [1-3]. Blood is described as a potent emetic [4], and the incidence of PONV has been reduced with pharyngeal packing (PP) in NS [5-7]. However, a recent study indicated that there is no need to place PP to prevent PONV in NS [8], while in theory, PP may prevent $\mathrm{PONV}$ by preventing PBI [9].

The aim of this study was to examine the effect of PP on the perioperative gastric volume (GV) by ultrasound and our hypothesis was that the reduction of PBI with PP would reduce the PONV incidence.

\section{Methods}

\section{Study design and participants}

The Bagcilar Training and Research Hospital NonInterventional Clinical Trials Ethics Committee approved this study $(2016 / 450)$. All participants were informed about the study protocol and provided written consent for study participation.

With the Sample Size Calculation; 5\% for error, 8\% power and standard impact size: $0.53, n=27$ cases were found sufficiently for each group. We started the study with $120(60+60)$ patients.

Patients aged $>18$ years with body mass indexes $<35$ $\mathrm{kg} / \mathrm{m}^{2}$ and with an American Society of Anesthesiologists physical status classification of I or II, underwent an elective NS [septoplasty, septo-rhinoplasty (SRP) and functional endoscopic sinus surgery (FESS)] under general anaesthesia after an $8 \mathrm{~h}$ preoperative fasting. The exclusion criteria were an emergent need for surgery; risk of an increased residual GV due to pregnancy, smoking, or diabetes; upper gastrointestinal system disease; and a history of oesophageal or upper gastrointestinal surgery. The patients were randomised to receive PP (group 2) or no PP (group 1). The flow of the patient enrolment is illustrated in Fig. 1.

The study was actualized from December 2016 to June 2017.

\section{Procedure}

Each patient was taken to the preoperative unit, and peripheral vascular access was established by a $20-G$ intravenous cannula. The patient was administered an intravenous infusion of $0.9 \% \mathrm{NaCl}(4 \mathrm{ml} / \mathrm{kg} / \mathrm{h})$. None of the patients were given any analgesic or sedative drug as premedication.

A preoperative ultrasonographic examination was performed, and then each patient was anaesthetised with fentanyl $(1 \mu \mathrm{g} / \mathrm{kg})$, propofol $(2-2.5 \mathrm{mg} / \mathrm{kg})$ and rocuronium $(0.6 \mathrm{mg} / \mathrm{kg})$. The same anaesthesiologist performed a laryngoscopy and an intubation for all patients. Following the orotracheal intubation, soft wet pharyngeal packs were placed with gentle manoeuvres to avoid damage to the soft palate in patients in group 2. The end of the pharyngeal pack was fixed to the

Assessed for eligibility $(n=120)$

Excluded (n=20)

$\sqcup$ Not meeting inclusion criteria $(\mathrm{n}=6)$

$\square$ Declined to participate $(n=14)$

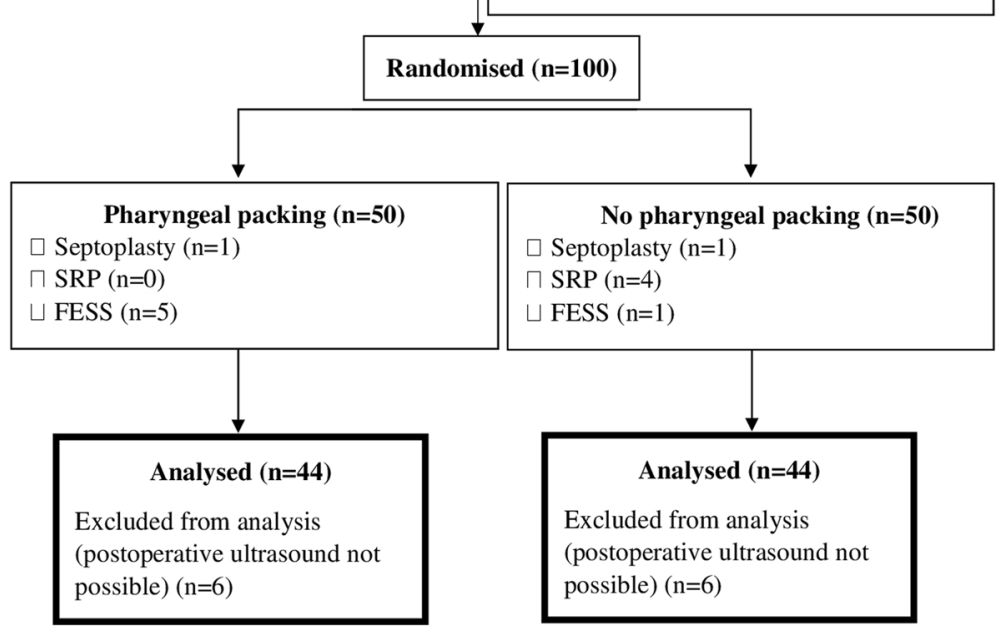

Fig. 1 Diagram of study flow. SRP, seprorhinoplasty; FESS, functional endoscopic sinus 
cheek with fastening bands such that it could be seen clearly. Patients were not administered prokinetic drugs in the perioperative period. Patients in both groups were intravenously administered ranitidine $(0.5 \mathrm{mg} / \mathrm{kg})$ following the intubation, and tenoxicam $(20 \mathrm{mg})$ and tramadol $(1 \mathrm{mg} / \mathrm{kg})$ at the end of the operation for postoperative analgesia.

After the completion of the postoperative ultrasonographic evaluation, the pharyngeal packs of the patients in group 2 were removed with the gentle removal of the fastening bands. Each patient was intravenously administered $0.5 \mathrm{mg}$ atropine and $1.5 \mathrm{mg}$ neostigmine. Patients underwent postoperative extubation in the operating room and were taken to the postoperative care unit. After achieving a Modified Aldrete Recovery Score of 9, the patients were transferred to the ward.

\section{Data collection and assessments}

The operation type and duration, and the demographic characteristics of each patient were recorded. In two separate sessions (before anaesthesia induction and before postoperative extubation; Figs. 2 and 3), an experienced radiologist with no knowledge of the group assignment and an anaesthesiologist, evaluated the stomach from the antrum by abdominal ultrasonography using a $2-5-\mathrm{MHz}$ convex probe and a Shenzhen ${ }^{\circ}$ Wed-380 system (China). Images of the stomach in a resting state were acquired between two peristaltic periods with the patient in the supine position. The postoperative examination visualised the epigastric region on the parasagittal plane. Three images were acquired from each session, and the mean antero-posterior (AP) and cranio-caudal (CC) diameters of the gastric antrum (in millimetres) were calculated. Then, the ACSA was calculated using the formula $\mathrm{CSA}=(\mathrm{AP} \times \mathrm{CC} \times 3.14) / 4$ [10]. The total volume of the stomach was then estimated using a previously tested and validated mathematical model with the following formula: GV (in millilitres) $=27+14.6 \times \mathrm{CSA}$ (in square millimetres) $-1.28 \times$ age [11].

For the comparison of PONV incidence and severity in groups 1 and 2, Kortilla's scale [12] was used: no PONV; absence of any emetic episode and nausea, mild PONV; mild nausea or one emetic episode or shortlasting ( $\sim 10 \mathrm{~min})$ nausea of any severity triggered by an exogenous stimulus (e.g. drinking, eating or postoperative movement) followed by diminished nausea and the patient's feeling well throughout the entire observation period with no antiemetic drug requirement, moderate PONV; one or two emetic episodes or moderate or severe nausea without exogenous stimulus or single requirement for antiemetic therapy, and severe PONV; more than two emetic or moderate to severe nauseous episodes requiring at least one antiemetic administration [13].

\section{Statistical analysis}

Statistical analyses were conducted using the 2007 Number Cruncher Statistical System software package (UT, USA). Descriptive statistics (means and standard deviations) were calculated. For normally distributed variables, a one-way analysis of variance was used to examine the differences between time points, and Tukey's multiple comparison test was used to examine differences between the groups. The unpaired $t$ test was used to analyse differences between the groups, and the paired $t$ test was used for a comparison of repeated measurements. For nonnormally distributed variables, the Kruskal-Wallis test was used for the comparison between the time points and Dunn's multiple comparison test was used to examine the differences between the subgroups. The Mann-Whitney

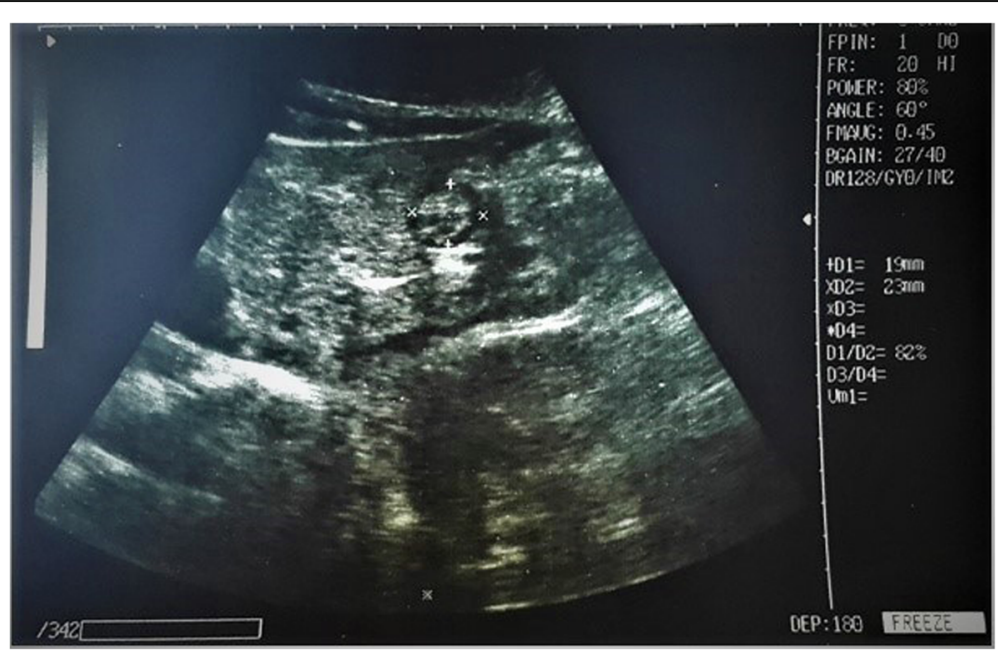

Fig. 2 Ultrasound image of the gastric antrum (epigastric region) in the parasagittal plane, obtained after $8 \mathrm{~h}$ fasting in the preoperative period 


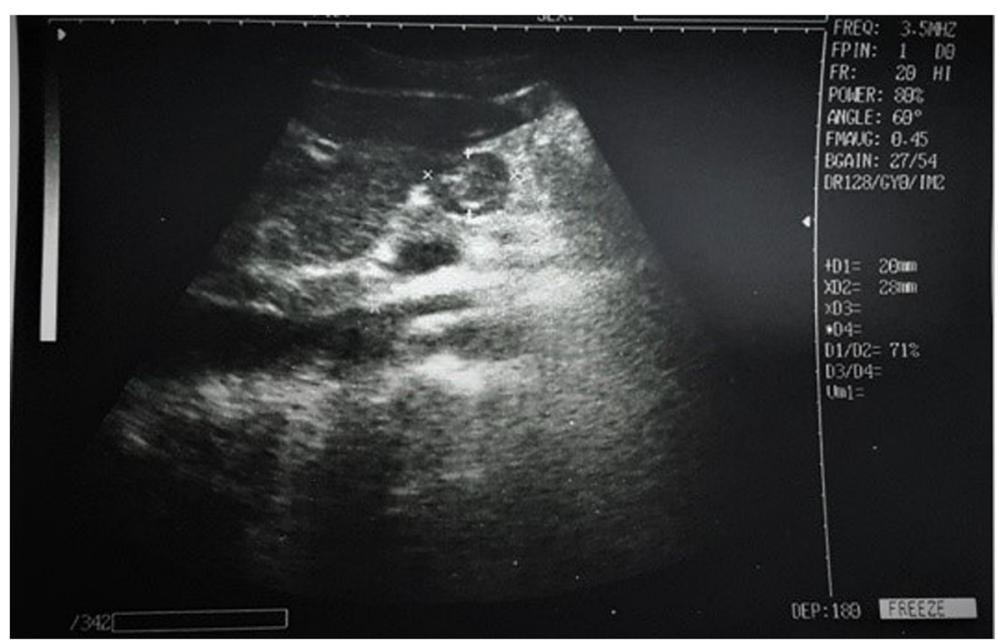

Fig. 3 Ultrasound image of the gastric antrum (epigastric region) in the parasagittal plane, obtained in the postoperative period

$U$ test was used to examine the differences between the groups. Qualitative data were examined using the chisquared test, and correlations between the variables were examined using the Pearson correlation analysis. $P$ values $<0.05$ were considered to be significant.

\section{Results}

Data from 88 patients ( $n=44 /$ group) were analysed in this study. Eight patients (four from each group) were excluded because ultrasonographic evaluation prior to extubation could not be performed due to severe gas. Four additional patients (two from each group) were excluded because postoperative gastric antrum imaging could not be performed due to the superposition of the transverse column. The demographic and surgical characteristics of the study sample are presented in Table 1.

In groups 1 and 2, AP and CC diameters, as well as ACSAs, were significantly larger in the postoperative period than in the preoperative period (all $p<0.05$ ). Postoperative AP and CC diameters and ASCAs were greater in group 1 than in group 2 (all $p<0.05$; Table 2 ). In patients undergoing SRP and FESS, postoperative AP diameters were greater than preoperative AP diameters (both $p<0.05$ ); no significant difference in this variable was observed in patients undergoing a septoplasty. The postoperative CC diameter and ACSA were significantly greater than preoperatively in patients undergoing SRP (both $p<0.05$ ), whereas no difference in these values was observed among patients undergoing a septoplasty and FESS (Table 3).

Positive correlations were found between the duration of surgery and the postoperative AP diameter $(r=0.380$, $p<0.05)$, postoperative CC diameter $(r=0.291, p<0.05)$, and postoperative ACSA $(r=0.369, p<0.05)$.
The incidence and severity of PONV are shown in Table 4.

\section{Discussion}

Pharyngeal packing is commonly performed following a tracheal intubation to reduce PBI and/or tracheal contamination during ear, nose and throat (ENT), and oral surgeries. Pharyngeal packs should absorb blood and provide a physical barrier preventing $\mathrm{PBI}$ and reducing the incidence of PONV [6]. Despite the common belief in the

Table 1 Demographic and surgical characteristics of the study groups

\begin{tabular}{llll}
\hline Characteristic & Group 1 $(n=44)$ & Group 2 $(n=44)$ & $p$ \\
\hline Age (years) & $30.18 \pm 8.98$ & $32.36 \pm 10.2$ & 0.285 \\
Sex & & & 0.658 \\
$\quad$ Male & $29(65.91)$ & $27(61.36)$ & \\
Female & $15(34.09)$ & $17(38.64)$ & \\
Weight (kg) & $69.24 \pm 12.64$ & $75.05 \pm 20.2$ & 0.110 \\
Height (cm) & $169.34 \pm 9.76$ & $166.14 \pm 17.77$ & 0.297 \\
BMI (kg/m $\left.{ }^{2}\right)$ & $24.28 \pm 4.13$ & $25.57 \pm 4.5$ & 0.164 \\
ASA physical status & & & 0.368 \\
I & $31(70.45)$ & $27(61.36)$ & \\
II & $13(29.55)$ & $17(38.64)$ & 0.360 \\
Surgery duration (min) & $100.91 \pm 48.02$ & $92.27 \pm 39.54$ & 0.251 \\
Surgery type & & & \\
Septoplasty & $15(34.09)$ & $16(36.36)$ & \\
Septo-rhinoplasty & $25(56.82)$ & $19(43.18)$ & \\
FESS & $4(9.09)$ & $9.45)$ & \\
\hline
\end{tabular}

Data are presented as mean \pm standard deviation or $n(\%)$ $B M I$ body mass index, ASA American Society of Anesthesiologists, FESS functional endoscopic sinus surgery 
Table 2 Ultrasonographically obtained gastric antrum data

\begin{tabular}{llll}
\hline Variable & Group 1 $(n=44)$ & Group 2 $(n=44)$ & $p$ \\
\hline Pre AP diameter $(\mathrm{mm})$ & $14.82 \pm 3.36$ & $15.25 \pm 3.72$ & $17 \pm 4.76$ \\
Post AP diameter $(\mathrm{mm})$ & $19.34 \pm 5.93$ & 0.569 \\
$p$ & 0.0001 & $21.66 \pm 5.31$ & 0.044 \\
Pre CC diameter $(\mathrm{mm})$ & $24.05 \pm 4.87$ & $23.45 \pm 6.45$ & 0.031 \\
Post CC diameter $(\mathrm{mm})$ & $29.09 \pm 8.37$ & 0.032 & 0.001 \\
$p$ & 0.0001 & $266.16 \pm 109.25$ & $324.83 \pm 155.54$ \\
Pre ACSA $\left(\mathrm{mm}^{2}\right)$ & $280.06 \pm 87.16$ & 0.005 & 0.511 \\
Post ACSA $\left(\mathrm{mm}^{2}\right)$ & $463.17 \pm 257.79$ & $7.56 \pm 17.6$ & 0.003 \\
P & 0.0001 & $5.16 \pm 19.08$ & 0.019 \\
Pre-Post AP diameter difference $(\%)$ & $18.38 \pm 24.48$ & $10.96 \pm 25.16$ & 0.052 \\
Pre-Post CC diameter difference $(\%)$ & $13.39 \pm 20.06$ & $58.56 \pm 131.79$ \\
Pre-Post ACSA difference $(\%)$ & $27.26 \pm 30.44$ & 0.007 \\
Pre-Post ACSA difference $\left(\mathrm{mm}^{2}\right)$ & $183.11 \pm 248.45$ & 0.004 \\
\hline
\end{tabular}

Data are presented as the mean \pm standard deviation

Pre preoperative, AP antero-posterior, Post postoperative, CC cranio-caudal, ACSA antral cross-sectional area

efficacy of PP, it does not offer 100\% protection against PBI [14]. In this study, postoperative gastric diameters and volume were increased in the postoperative period in patients who did and did not receive PP, but were greater in patients not treated with PP. Thus, patients undergoing NS who received PP ingested less blood and secretions into the stomach, than those not treated with PP. This finding is clinically meaningful in two ways. First, the perioperative ingestion of secretions and blood may result in the risk of postoperative pulmonary aspiration due to an increased GV [15-17]. Second, it can increase the incidence of PONV $[18,19]$. Although some researchers have found that PP does not reduce PONV, and that it increases postoperative aphthous stomatitis and sore throat [3], many anaesthesiologists believe that PP prevents PONV by creating a physical barrier for the entry of blood from the throat into the stomach during NS $[6,15]$. In our study, only patients who underwent septoplasty surgery, PP was decreased PONV incidence and severity at the first four hours, postoperatively.

Van de Putte and Perlas [20] confirmed the mathematical model for the gastroscopic and ultrasonographic evaluation of GV and published the formula used in this study for the right lateral decubitus position. According to this formula, a GV $<1.5 \mathrm{ml} / \mathrm{kg}$ reflects a low pulmonary aspiration risk [21, 22]. Arzola et al. [23] performed bedside a gastric ultrasonographic evaluation after $8 \mathrm{~h}$ fasting, with patients with term pregnancies in the right lateral decubitus position prior to an elective caesarean section; they calculated GVs using the above-mentioned formula. In 2011, Bouvet et al. [24] evaluated correlations between the GV and ACSA obtained by an ultrasonographic measurement with patients in the supine position. They reported preoperative ACSAs of $280 \pm$ $115 \mathrm{~mm}^{2}$ and $581 \pm 294 \mathrm{~mm}^{2}$ in elective and emergent patients, respectively, and proposed a supine ACSA cut-

Table 3 Ultrasonographic data according to surgery type

\begin{tabular}{|c|c|c|c|c|}
\hline & Septoplasty $(n=31)$ & $\operatorname{SRP}(n=44)$ & FESS $(n=13)$ & $p$ \\
\hline Pre AP diameter (mm) & $14.81 \pm 3.87$ & $15.23 \pm 3.53$ & $14.92 \pm 2.84$ & 0.875 \\
\hline Post AP diameter (mm) & $15.71 \pm 4.55$ & $19.89 \pm 5.95$ & $18.23 \pm 3.52$ & 0.004 \\
\hline$p$ & 0.056 & 0.0001 & 0.016 & \\
\hline Pre CC diameter (mm) & $22.71 \pm 5.11$ & $22.8 \pm 5.12$ & $23.38 \pm 6.06$ & 0.923 \\
\hline Post CC diameter (mm) & $23.55 \pm 6.01$ & $28.8 \pm 9.11$ & $24.23 \pm 4.85$ & 0.01 \\
\hline$p$ & 0.133 & 0.0001 & 0.688 & \\
\hline Pre CSA diameter $\left(\mathrm{mm}^{2}\right)$ & $267.19 \pm 102.23$ & $274.52 \pm 96.33$ & $282.47 \pm 103.81$ & 0.890 \\
\hline Post CSA diameter $\left(\mathrm{mm}^{2}\right)$ & $299.22 \pm 145.53$ & $472.73 \pm 260.01$ & $353.54 \pm 130.36$ & 0.002 \\
\hline$p$ & 0.066 & 0.0001 & 0.135 & \\
\hline
\end{tabular}

Data are presented as the mean \pm standard deviation

SRP septo-rhinoplasty, ESS functional endoscopic sinus surgery, Pre preoperative, AP antero-posterior, Post postoperative, CC cranio-caudal, CSA cross-sectional area 
Table 4 Incidence and severity of PONV after surgery

\begin{tabular}{|c|c|c|c|c|c|c|c|c|}
\hline \multirow{2}{*}{$\begin{array}{l}\text { Surgery } \\
\text { Septoplasty }(n=31)\end{array}$} & \multirow{2}{*}{$\frac{\text { Time after surgery (h) }}{2}$} & \multicolumn{3}{|c|}{ Group $2(n=44)$} & \multicolumn{3}{|c|}{ Group $1(n=44)$} & \multirow[t]{2}{*}{$p$} \\
\hline & & $37.5 \%$ & Severe & $15 \%$ & $60 \%$ & Severe & $25 \%$ & \\
\hline & & & Moderate & $15 \%$ & & Moderate & $15 \%$ & 0.378 \\
\hline & & & Mild & $7.5 \%$ & & Mild & $20 \%$ & \\
\hline & 4 & $18.8 \%$ & Severe & $10 \%$ & $60 \%$ & Severe & $20 \%$ & \\
\hline & & & Moderate & $3.8 \%$ & & Moderate & $12 \%$ & 0.046 \\
\hline & & & Mild & $5 \%$ & & Mild & $28 \%$ & \\
\hline & 8 & $50 \%$ & Severe & $10 \%$ & $53.3 \%$ & Severe & $8 \%$ & \\
\hline & & & Moderate & $15 \%$ & & Moderate & $14 \%$ & 0.862 \\
\hline & & & Mild & $25 \%$ & & Mild & $31.3 \%$ & \\
\hline & 24 & $0 \%$ & Severe & $0 \%$ & $13.3 \%$ & Severe & $1.3 \%$ & \\
\hline & & & Moderate & $0 \%$ & & Moderate & $2 \%$ & 0.226 \\
\hline & & & Mild & $0 \%$ & & Mild & $10 \%$ & \\
\hline \multirow[t]{12}{*}{$\operatorname{SRP}(n=44)$} & 2 & $50 \%$ & Severe & $20 \%$ & $50 \%$ & Severe & $30 \%$ & \\
\hline & & & Moderate & $15 \%$ & & Moderate & $20 \%$ & 0.762 \\
\hline & & & Mild & $15 \%$ & & Mild & $10 \%$ & \\
\hline & 4 & $40 \%$ & Severe & $15 \%$ & $41.7 \%$ & Severe & $20 \%$ & \\
\hline & & & Moderate & $10 \%$ & & Moderate & $11.7 \%$ & 0.845 \\
\hline & & & Mild & $15 \%$ & & Mild & $10 \%$ & \\
\hline & 8 & $25 \%$ & Severe & $5 \%$ & $33.3 \%$ & Severe & $20 \%$ & \\
\hline & & & Moderate & $10 \%$ & & Moderate & $8.3 \%$ & 0.786 \\
\hline & & & Mild & $10 \%$ & & Mild & $5 \%$ & \\
\hline & 24 & $5 \%$ & Severe & $0 \%$ & $16.7 \%$ & Severe & $6.7 \%$ & \\
\hline & & & Moderate & $0 \%$ & & Moderate & $5 \%$ & 0.461 \\
\hline & & & Mild & $5 \%$ & & Mild & $5 \%$ & \\
\hline \multirow[t]{12}{*}{ FESS $(n=13)$} & 2 & $40.9 \%$ & Severe & $15 \%$ & $54.5 \%$ & Severe & $30 \%$ & \\
\hline & & & Moderate & $20 \%$ & & Moderate & $14.5 \%$ & 0.286 \\
\hline & & & Mild & $5.9 \%$ & & Mild & $10 \%$ & \\
\hline & 4 & $29.5 \%$ & Severe & $10 \%$ & $47.7 \%$ & Severe & $20 \%$ & \\
\hline & & & Moderate & $14.5 \%$ & & Moderate & $19.7 \%$ & 0.126 \\
\hline & & & Mild & $5 \%$ & & Mild & $5 \%$ & \\
\hline & 8 & $31.8 \%$ & Severe & $16.8 \%$ & $38.6 \%$ & Severe & $12 \%$ & \\
\hline & & & Moderate & $12 \%$ & & Moderate & $14 \%$ & 0.655 \\
\hline & & & Mild & $3 \%$ & & Mild & $10.8 \%$ & \\
\hline & 24 & $2.3 \%$ & Severe & $0 \%$ & $15.9 \%$ & Severe & $6 \%$ & \\
\hline & & & Moderate & $0 \%$ & & Moderate & $8 \%$ & 0.064 \\
\hline & & & Mild & $0 \%$ & & Mild & $1.9 \%$ & \\
\hline
\end{tabular}

PONV postoperative nausea and vomiting, SRP seprorhinoplasty, FESS functional endoscopic sinus surgery

off value of approximately $340 \mathrm{~mm}^{2}$ for $0.8 \mathrm{ml} / \mathrm{kg} \mathrm{GV}$, which determined the aspiration risk with a sensitivity of $91 \%$ and a negative predictive value of $94 \%$. In our study, preoperative ACSAs exceeded this cut-off in 21 of 88 (23.8\%) patients. Pharygeal packing in elective NS may prevent the development of GVs carrying a postoperative pulmonary aspiration risk (threshold, $0.8 \mathrm{~mL} / \mathrm{kg}$ ) by $77 \%$. However, the critical cut-off value for GV with regard to an aspiration risk must be discussed. The critical threshold for this risk has been reported to be $0.4-0.8$ $\mathrm{ml} / \mathrm{kg} \quad(28-56 \mathrm{ml} / 70 \mathrm{~kg}) \quad[20,25]$, but the $0.8 \mathrm{ml} / \mathrm{kg}$ threshold is probably insufficient because regurgitation and aspiration of a minimum of $200 \mathrm{ml} \mathrm{GV}$ are required for pulmonary damage [26]. Residual GVs in healthy, hungry patients can be $\geq 1.5 \mathrm{ml} / \mathrm{kg}$ [27]. The pathophysiology of pulmonary aspiration during general 
anaesthesia is complex and associated with various risk factors (e.g. difficult airway management, inappropriate anaesthesia technique, straining, coughing, gastrooesophageal reflux) [28].

There are some major limitations in this study that could be adressed in future researches. First, there were a few patients in the different nasal surgeries' groups. Second, we did not examine the correlation between GV and PONV. Third, we did not investigate whether the duration of NS increased the GV. Fourth, we did not calculate GV using a confirmed mathematical method developed for use with angles measured in the supine position and antral CSA. Further studies are needed to evaluate the relationship between PP and perioperative pulmonary aspiration risk, and between postoperative GV and PONV. A larger sample size and different nasal surgery population need to be researched for the outcome.

\section{Conclusions}

In conclusion, PP reduces the increase in the perioperative GV due to PBI in elective NS. It prevents the possible aspiration of blood into the aerodigestive tract. Although PP implementation is advantageous for anaesthesiologists, it seems to be disadvantageous for ENT surgeons. Cooperation is needed for this issue. Bedside ultrasound examination can aid such cooperation, enabling a determination of the degree of stomach fullness for anaesthesiologists and ENT surgeons in the operating room. Gastric volume evaluation before extubation plays a very important role, guiding decisions about gastric decompression. An increased GV is a marker of perioperative pulmonary aspiration and PONV risk. We believe that PP is a useful and safe means of reducing the risk of perioperative pulmonary aspiration in NS.

\section{Abbreviations}

ACSA: Antral cross-sectional area; AP: Antero-posterior; CC: Cranio-caudal; ENT: Ear, nose and throat; FESS: Functional endoscopic sinus surgery; GV: Gastric volume; NS: Nasal surgery; PBI: Perioperative blood ingestion; PONV: Postoperative nausea and vomiting; PP: Pharyngeal packing; SRP: Septo-rhinoplasty

\section{Acknowledgements}

Not applicable.

\section{Authors' contributions}

Conception: MET, KE, TT, GST, AS Design: MET, KE, GST, TT, AS. Supervision: MET, AS, GST, KE, TT. Fundings: MET, TT, GST, KE, AS. Materials: MET, KE, GST, $\Pi$, AS Data collection and/or processing: MET, KE, TT, GST, AS. Analysis and/ or interpretation: MET, TT, AS, KE, GST. Literature review: MET, TT, GST, KE, AS. Writer: MET, KE, GST, TT, AS. Critical review: MET, KE, AS, TT, GST. AND, all authors read and approved the final version of the manuscript.

\section{Funding}

None.

\section{Availability of data and materials}

The datasets used and/or analysed during the current study are available from the corresponding author upon reasonable request.

\section{Ethics approval and consent to participate}

The Bagcilar Training and Research Hospital Non-Interventional Clinical Trials Ethics Committee approved this study (2016/450). All participants were informed about the study protocol and provided written consent to participate in the study.

\section{Consent for publication}

Not applicable.

\section{Competing interests}

The authors declare that they have no competing interests.

\section{Author details}

${ }^{1}$ Tekirdag Corlu State Hospital, Corlu, Turkey. ${ }^{2}$ Nisantasi University, Istanbul Safak Hospital, Istanbul, Turkey. ${ }^{3}$ Health Sciences University, Istanbul Bagcilar Training and Educational Hospital, Istanbul, Turkey.

Received: 16 January 2019 Accepted: 17 June 2019

Published online: 08 July 2019

\section{References}

1. Gan TJ. Risk factors for postoperative nausea and vomiting. Anesth Analg. 2006;102(6):1884-98

2. Al-Lami A, Amonoo-Kuofi K, Kulloo P, Lakhani R, Prakash N, Bhat N. A study evaluating the effects of throat packs during nasal surgery: a randomised controlled trial. Eur Arch Otorhinolaryngol. 2017:274(8):3109-14.

3. Erkalp K, Korkut YA, Meric A, Kahya V, Gedikli O, Su OK, et al. Pharyngeal packing is a predisposing factor for postoperative aphthous stomatitis in nasal surgery. Otolaryngol Head Neck Surg. 2010;142(5):672-6.

4. Razavi M, Gilani MT, Bameshki AR, Behdani R, Khadivi E, Bakhshaee M. Pharyngeal packing during rhinoplasty: advantages and disadvantages. Iran J Otorhinolaryngol. 2015;27(6):423-8.

5. Meco BC, Ozcelik M, Yildirim Guclu C, Beton S, Islamoglu Y, Turgay A, et al. Does type of pharyngeal packing during sinonasal surgery have an effect on PONV and throat pain? Otolaryngol Head Neck Surg. 2016;154(4):742-7.

6. Basha SI, McCoy E, Ullah R, Kinsella JB. The efficacy of pharygeal packing during routine nasal surgery-a prospective randomised controlled study. Anaesthesia. 2006;61:1161-5.

7. Alfiky MG, Margalani OA, Rajeh AF, Alghamdi FE, Abu Suliman OA, Muathen $\mathrm{SH}$, et al. Nasopharyngeal versus hypopharyngeal packing during sino-nasal surgeries: Randomised controlled trial. Clin Otolaryngol. 2018;43(5):1235-41.

8. Jin HJ, Kim S, Hwang SH. Can pharyngeal packing prevent postoperative nausea and vomiting in nasal surgery? Laryngoscope. 2019;129(2):291-9.

9. Green R, Konuthula N, Sobrero M, Saini A, Parasher A, Pool C, et al. Use of pharyngeal packs in functional endoscopic sinus surgery: a randomized controlled trial. Larygoscope. 2017;127(11):2460-5.

10. Perlas A, Chan WW, Lupu CM, Mitsakakis N, Hanbidge A. Ultrasound assessment of gastric content and volume. Anesthesiology. 2009:111:82-9.

11. Van de Putte $P$, Vernieuwe $L$, Jerjir $A$, Verschueren $L$, Tacken $M$, Perlas A. When fasted is not empty: a retrospective cohort study of gastric content in fasted surgical patients. Br J Anaesth. 2017;118(3):363-71.

12. Korttila K. The study of postoperative nausea and vomiting. Br J Anaesth. 1992;69:20-3.

13. Erkalp K, Erkalp NK, Sevdi MS, Korkut AY, Yeter H, Ege SS, et al. Gastric decompression decreases postoperative nausea and vomiting in ENT surgery. Int J Otolarnygology. 2014;143:831-6.

14. Sexton J, Dohlman L. Benefits of the pharygeal pack. J Oral Maxillofac Surg. 1989:47:891

15. Bajwa SJ. Prevention of aspiration of blood with a unique pharyngeal packing method. Anesth Essays Res. 2012;6(2):251-2.

16. Rizvi MM, Singh RB, Rasheed MA, Sarkar A. Effects of different types of pharyngeal packing in patients undergoing nasal surgery: A comparative study. Anesth Essays Res. 2015;9(2):230-7.

17. Appadurai $I R$, Tomkins A. Pharyngeal packing during ENT surgery. Anaesthesia. 2007:62:633-4.

18. Piltcher O, Lavinsky M, Lavinsky J, de Oliveira Basso PR. Effectiveness of hypopharyngeal packing during nasal and sinus surgery in the prevention of PONV. Otolaryngol Head Neck Surg. 2007:137(4):552-4.

19. Korkut AY, Erkalp K, Erden V, Teker AM, Demirel A, Gedikli O, Saidoglu L. Effect of pharyngeal packing during nasal surgery on postoperative nausea and vomiting. Otolaryngol Head Neck Surg. 2010;143(6):831-6. 
20. Van de Putte P, Perlas A. Ultrasound assessment of gastric content and volume. Br J Anaesth. 2014;113(1):12-22.

21. Engelhardt T, Webster NR. Pulmonary aspiration of gastric contents in anaesthesia. Br J Anaesth. 1999;83:453-60.

22. Raidoo DM, Rocke DA, Brock-Utne JG, Marszalek A, Engelbrecht HE. Critical volume for pulmonary acid aspiration: reappraisal in a primate model. $\mathrm{Br} J$ Anaesth. 1990;65:248-50.

23. Arzola C, Perlas A, Siddiqui NT, Carvalho JC. Bedside gastric ultrasonography in term pregnant woman before elective cesarean delivery: a prospective cohort study. Anesth Analg. 2015;121(3):752-8.

24. Bouvet L, Mazoit JX, Chassard D, Allaouchiche B, Boselli E, Benhamou D. Clinical assessment of the ultrasonographic measurement of antral area for estimating preoperative gastric content and volume. Anesthesiology. 2011; 114(5):1086-92.

25. Bisinotto FM, Pansani PL, Silveira LA, Naves AA, Peixoto AC, Lima HM, Martins LB. Qualitative and quantitative ultrasound assessment of gastric content. Rev Assoc Med Bras. 2017;63(2):134-41.

26. Bouvet L, Miquel A, Chassard D, Boselli E, Allaouchiche B, Benhamou D. Could a single standardized ultrasonographic measurement of antral area be of interest for assessing gastric contents? A preliminary report. Eur J Anaesthesiol. 2009;26(12):1015-9.

27. Perlas A, Davis L, Khan M, Mitsakakis N, Chan WW. Gastric sonography in the fasted surgical patient: a prospective descriptive study. Anesth Analg. 2011; 113(1):93-7.

28. Kluger MT, Short TG. Aspiration during anaesthesia: a review of 133 cases from the Australian Anaesthetic incident monitoring study (AIMS). Anaesthesia. 1999;54:19-26.

\section{Publisher's Note}

Springer Nature remains neutral with regard to jurisdictional claims in published maps and institutional affiliations.

Ready to submit your research? Choose BMC and benefit from:

- fast, convenient online submission

- thorough peer review by experienced researchers in your field

- rapid publication on acceptance

- support for research data, including large and complex data types

- gold Open Access which fosters wider collaboration and increased citations

- maximum visibility for your research: over $100 \mathrm{M}$ website views per year

At $\mathrm{BMC}$, research is always in progress.

Learn more biomedcentral.com/submissions 